\title{
ANALYSIS OF DAMAGE PREDICTION IN LAMINATED COMPOSITES SUBJECTED TO IMPACT LOADING
}

\author{
Mohamed Fayas Saffiudeen ${ }^{1}$ \\ ${ }^{1}$ Lecturer, Department of Mechanical Skills, Jubail Technical Institute, Royal Commission of Jubail, \\ Jubail Industrial city-31961, Jubail-Kingdom of Saudi Arabia
}

\author{
Abdullah Syed ${ }^{2}$ \\ ${ }^{2}$ Lecturer, Department of Mechanical Skills, Jubail Technical Institute, Royal Commission of Jubail, \\ Jubail Industrial city-31961, Jubail-Kingdom of Saudi Arabia \\ Fasil T. Mohammed ${ }^{3}$ \\ ${ }^{3}$ Lecturer, Department of Mechanical Skills, Jubail Technical Institute, Royal Commission of Jubail, \\ Jubail Industrial city-31961, Jubail-Kingdom of Saudi Arabia
}

Article DOI: https://doi.org/10.36713/epra4128

\begin{abstract}
Fibre-reinforced laminated composites are susceptible to transverse impact, at low velocities causing significant damage, in terms of matrix cracks and delamination's, which are very difficult to detect with the naked eye and can cause significant reductions in the strength and stiffness of the materials. This study aimed at analysing the transient dynamic response of laminated composites due to impact. The effect of fiber volume fraction, laminate thickness, plate boundary conditions, velocity and mass of impactor on the behaviour of composites during low velocity impact is analysed using ABAQUS software.

For the analysis, a laminated composite panel made of graphite/epoxy fiber-reinforced laminates is subjected to transverse impact by projectile with a spherical nose. Hashin failure model was adopted for the analysis.

The optimal fiber capacity fraction for extreme impact energy for T300/976 type of composite was determined. The velocity required to cause damage initiation was found out for different fiber volume fractions. The variation of contact force and central deflection with velocity and mass of impactor was determined and appropriate empirical models were developed to predict the maximum contact force and central deflection for particular values of impactor velocity and mass. The variation of resistance to failure with laminate thickness was found out and suitable boundary conditions of the plate were identified for different types of impact loading

INDEX TERMS—Fiber Reinforced laminated Composite, impactor mass, contact force central deflection
\end{abstract}




\section{EPRA International Journal of Research and Development (IJRD)

\section{I.INTRODUCTION}

In the past few years, laminated composite materials have been used extensively due to their high-strength and light-weight features. However, their behaviour under foreign object impact is of great concern since the impact-induced damage can significantly reduce the strength of the structure. A preliminary step in understanding the effect of impact is to develop models for predicting the overall response of the structure. Since the impact response depends not only on the material properties but also on the dynamic behaviour of the impacted structure, it is very important to have a basic understanding of the structural response under impact as well as how it is affected by different parameters. An efficient approach to study the effect of impact on composite structures is to separately analyse two aspects of impact: impact damage resistance and impact damage tolerance. Impact damage resistance addresses the response and damage of the structures caused by impact. On the other hand, impact damage tolerance deals with the effect of existing impact damage on the strength and stability of the structures. The impact damage resistance of composite laminates is investigated throughout this study. Figure 1 schematically shows the various failures possible in layered composites due to point load impact.

Significant research efforts on impact damage resistance of composite structures have been conducted in the last few decades. This subject has been thoroughly reviewed by Sun and Yang. (1980). Most of the studies are based on the Hertzian contact law, which was originally developed for static loading on an isotropic linear elastic half-space. Permanent deformation associated with damage was not accounted for in the Hertzian contact law. Therefore, a contact law incorporating effects of damage is needed for accurate modeling of contact force-deformation during impact. It is also necessary to develop analytical or semi-analytical approaches to better understand the behaviours of composite structures under impact and associated failure processes.

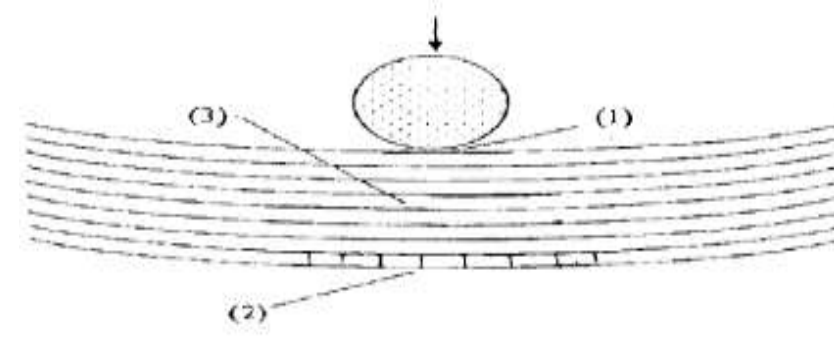

(1) Compressive failure

(2) Tensile failure

(3) Shear-driven delaminations

Figure 1 Failure due to point-loading impact

\section{II.RESEARCH OBJECTIVES}

To investigate the dynamic response of composite laminates under low velocity impact.

To predict the initiation of damages in composite structures.

To predict the effect of material properties, laminate thickness, plate boundary conditions, velocity and mass of impactor, on the impact damage.

To develop empirical models to predict the contact force and central deflection of the composite plate for a particular impactor mass and velocity.

\section{III.LITERATURE SURVEY}

An investigation was performed by Hyung Yun Choi and $\mathrm{Fu}$ Kuo Chang (1992), to study the impact damage of graphite/ epoxy laminated composites caused by low velocity foreign object. A transient dynamic finite element analysis is presented by Hsi Yung, Wu and Fu-Kuo Chang (1989), for studying the response of laminated composite plates due to transverse foreign object impact. The analysis can be used to calculate displacements of composite plate during impact and the transient stress and strain distributions through the laminate thickness. Ramazan Karakuzu et. al (2010), studied the impact behaviour of glass/ epoxy laminated composite plates with a specified fiber orientation at equal energy, equal velocity and equal impactor mass. In order to examine the stacking sequence effect, five different fiber orientations were chosen. Three different plate thicknesses were also selected to survey the thickness effect on impact behaviour of glass/ epoxy composite plates. Composite failure criteria have been developed by Chian-Fong Yen et. al (2007), for dynamic analysis of composite structures. The proposed progressive failure criteria have been integrated into an explicit dynamic analysis code for failure prediction of thin composite tubes subjected to drop weight impact tests. The results provide good correlation with experimental data for impact force histories and some critical damage modes. Details regarding the Hashin failure criteria were given in these analyses which were later adopted in this project work. Computational model of pseudo-damage induced stiffness parameters and static load-deflection response was developed by Umar Farooq and Karl Gregory (2008), to study the initiation and propagation of barely visible impact damage (BVID) and failure prediction of composite panels. Failure load and failure mode of woven glass epoxy composite plates with one and two serial pinned joints are analysed experimentally and numerically by Alaattin Aktas (2011). Two variables are investigated during analysis, the distance from the free edge of the plate to the diameter of the first hole (E/D) ratio, and the width of the specimen to the diameter of the holes (W/D) ratios. Experiments are 


\section{EPRA International Journal of Research and Development (IJRD)

carried out according to the ASTM D953. Numerical study is performed by means of ANSYS finite element analysis program. Yamada Sun failure criterion is used for failure analysis. Mechanical properties of the composite material are obtained from the ASTM standards. The results showed a fair agreement between experimental results and numerical predictions. Perez et.al (2011) used new standardized tests to assess the impact tolerance using ASTM D7136 and D7137. Tiberkak et.al (2008) studied fiber-reinforced composite plates subjected to low velocity impact by using finite element analysis. The use of interface finite elements and a damage model are proposed by De Moura and Goncalves (2004), to predict damage due to low velocity impact in carbon- epoxy $(04,904) \mathrm{s}$ laminates

\section{IV.PROBLEM DEFINITION}

Consider a laminated composite panel made of graphite/epoxy fiber-reinforced pre-pregs and subjected to transverse impact by a low-velocity projectile with a spherical nose as shown in Figure 2. The ply orientation of the laminate can be arbitrary but must be symmetric with respect to its middle plane.

For a given mass of the impactor, the following are to be determined: the impact damage

The velocity of the impactor required to initiate

The effect of Fiber volume fraction, thickness of laminate and mass of impactor on the behavior of composites during impact

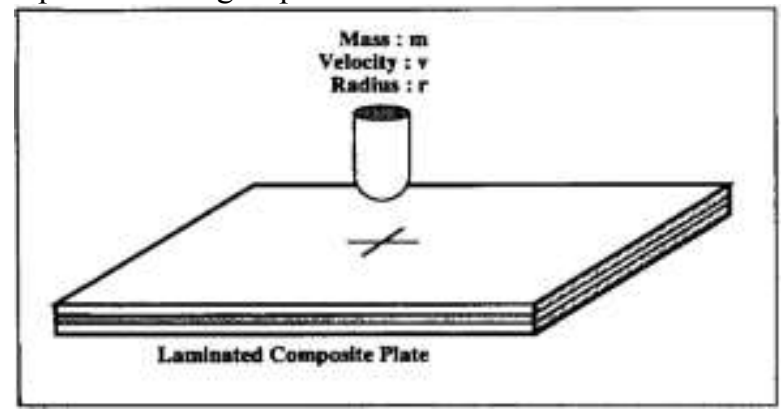

Figure 2 laminated composite panel subjected to A. Material Used transverse impact

In order to conduct the analysis, a spherical steel impactor and T300/976 composites were selected. The details are given below

\section{B. Composite Test Specimen \\ Table I: Ply orientations and geometries of the test specimens}

\begin{tabular}{|c|c|c|c|c|}
\hline Material & $\begin{array}{c}\text { Ply } \\
\text { orientation }\end{array}$ & $\begin{array}{c}\text { Thick } \\
\text { (mm) }\end{array}$ & $\begin{array}{c}\text { Span } \\
\text { length } \\
\text { (mm) }\end{array}$ & $\begin{array}{c}\text { Width } \\
\text { (mm) }\end{array}$ \\
\hline $\begin{array}{c}\text { T300/976 } \\
\text { Graphite/ } \\
\text { Epoxy }\end{array}$ & $\begin{array}{c}{\left[45^{\circ} / 0^{\circ} /-\right.} \\
\left.45^{\circ} / 90^{\circ}\right] 5 \mathrm{~s}\end{array}$ & 6 & 150 & 100 \\
\hline
\end{tabular}

\section{T300/976 Composite}

Table II: Material properties of fiber and matrix

\begin{tabular}{|c|c|c||c|c|c|}
\hline \multicolumn{3}{|c||}{ Fiber } & \multicolumn{3}{c|}{ Matrix } \\
\hline Property & Value & Unit & Property & Value & Unit \\
\hline $\mathrm{E}_{11}$ & 220 & $\mathrm{GPa}$ & $\mathrm{E}_{\mathrm{m}}$ & 3.45 & $\mathrm{GPa}$ \\
\hline $\mathrm{E}_{22}$ & 14 & $\mathrm{GPa}$ & $\mathrm{G}_{\mathrm{m}}$ & 1.28 & $\mathrm{GPa}$ \\
\hline $\mathrm{G}_{12}=\mathrm{G}_{13}$ & 9 & $\mathrm{GPa}$ & $v_{\mathrm{m}}$ & 0.35 & \\
\hline $\mathrm{G}_{23}$ & 4.6 & $\mathrm{GPa}$ & $\mathrm{X}_{\mathrm{m}}{ }^{\mathrm{t}}$ & 90 & $\mathrm{MPa}$ \\
\hline$v_{12}=v_{13}$ & 0.2 & & $\mathrm{X}_{\mathrm{m}}{ }^{\mathrm{c}}$ & 130 & $\mathrm{MPa}$ \\
\hline$v_{23}$ & 0.25 & & $\mathrm{X}_{\mathrm{m}}{ }^{\mathrm{s}}$ or $\mathrm{X}_{\mathrm{s}}$ & 60 & $\mathrm{MPa}$ \\
\hline $\mathrm{X}_{11}{ }^{\mathrm{t}}$ & 2415 & $\mathrm{MPa}$ & $\rho$ & 1.3 & $\mathrm{~g} / \mathrm{cc}$ \\
\hline $\mathrm{X}_{11}{ }^{\mathrm{c}}$ & 1800 & $\mathrm{MPa}$ & & & \\
\hline $\mathrm{X}_{12}$ or $\mathrm{X}_{\mathrm{s}}$ & 550 & $\mathrm{MPa}$ & & & \\
\hline$\rho$ & 1.77 & $\mathrm{~g} / \mathrm{cc}$ & & & \\
\hline
\end{tabular}

\section{V.ANALYSIS USING ABAQUS}

Dynamic explicit analysis was performed to determine the critical velocity at which damage initiation occurs. Plane stress condition was chosen and the composite plate was modeled as a shell element with S4R type elements. Material behaviour is assumed to be orthotropic and surface to surface interaction was assumed for the analysis. The composite plate was fixed on all four edges and the impactor was modeled as analytical rigid body. Material properties were calculated for different fiber volume fractions using Mechanics of Materials approach and analysis was conducted.

\section{A. Modeling of Composite}

The composite was modeled as a 40 ply [45/0/45/90]5S composite. The ply stack plot of the composite generated in ABAQUS is shown in Figure 3 


\section{EPRA International Journal of Research and Development (IJRD)

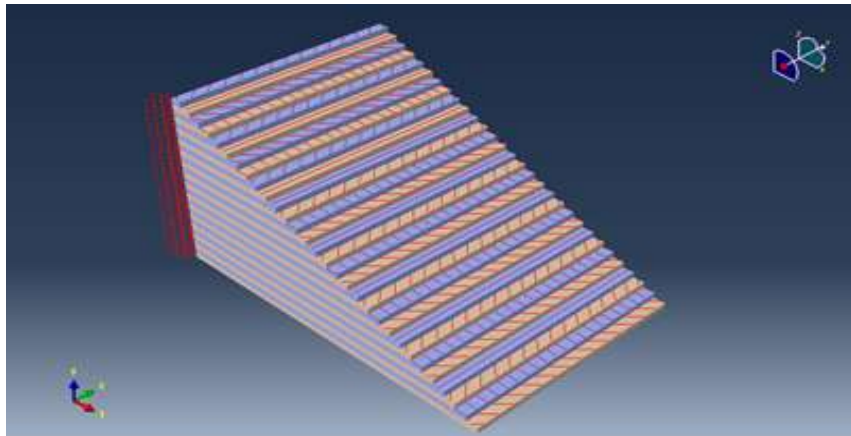

Figure 3 Ply stack plot

\section{B. Assembly Module}

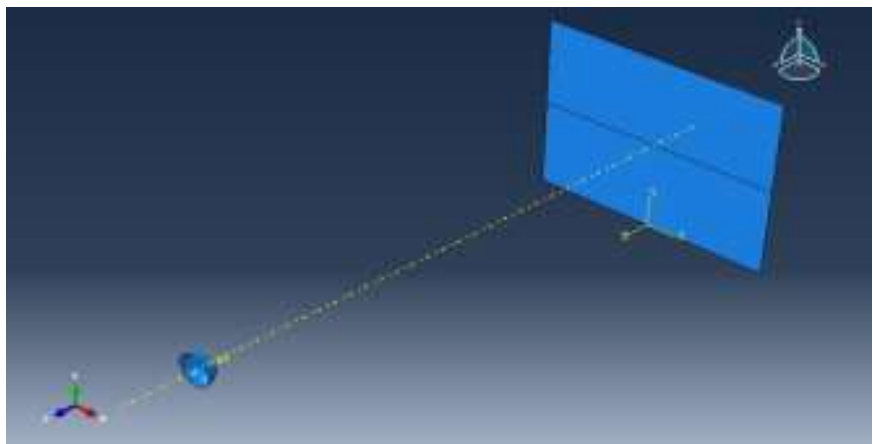

Figure 4 The assembly view port specifying the initial positioning of the interacting instances

\section{Definition of Surfaces}

The interacting surfaces of the sphere and the composite plate were specified Frictionless contact was assumed between the two surfaces during impact.

\section{Loading and Boundary Conditions}

The composite plate was fixed on all the four sides and a velocity was applied on the spherical impactor as shown in Figure 5

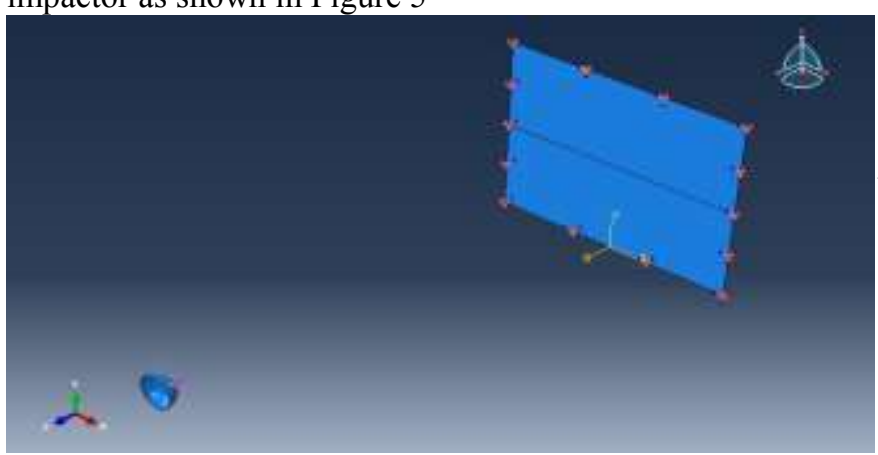

Figure 5 loading and boundary conditions

\section{E. Meshing}

Mesh was generated using linear quadrilateral elements of type S4R for the composite plate and the spherical impactor was modeled as an analytical shell. A total number of 945 nodes and 884 numbers of elements were generated for the analysis. The mesh generation viewport is shown in Figure 6

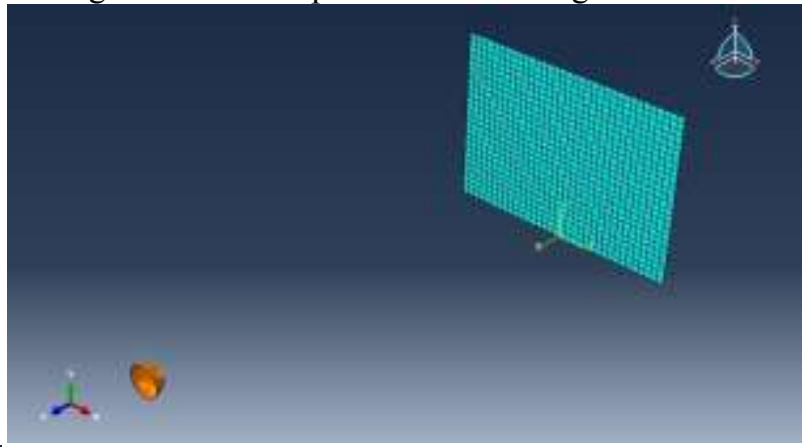

Figure 6 Mesh generation

\section{VI.VALIDATION OF ANALYSIS PROCEDURE} A. Procedure

In order to check the correctness of the analysis procedure, a comparative survey was undertaken with respect to other instrumented impact tests data published in the literature. Perez et.al (2011) used new standardized tests to assess the impact tolerance using ASTM D7136 and D7137. The experimental output was collected from this literature and was used for validation.

Analysis was done using $150 \times 100 \mathrm{~mm}$ graphite epoxy composite plates with a fiber volume fraction of $58 \%$. Its construction consists of 40 unidirectional T300 carbon fiber reinforced epoxy plies with a symmetric stacking sequence $\left[45^{\circ} / 0^{\circ} /-45^{\circ} / 90^{\circ}\right]_{5 \mathrm{~s}}$, which achieve a total cured thickness near to $6 \mathrm{~mm}$ with a uniform cross-section over the entire surface. The laminated plate layup is defined such that the $0^{\circ}$ fiber orientation is aligned with the lengthwise dimension. The impactor used was hemispherical in shape with a diameter of $16 \mathrm{~mm}$ and a mass of $2.24 \mathrm{~kg}$ as per ASTM D7136. The experimental results of Perez et.al (2011) is shown in Figure 7. From the figure, it is quite evident that damage initiation occurs in the composite at impact energy of $15 \mathrm{~J}$.

Since damage initiation is the primary concern in this project, analysis was conducted to verify the compliance of the result to this damage initiation threshold and the percentage error in analysis was determined. 


\section{EPRA International Journal of Research and Development (IJRD) \\ Volume: 5 | Issue: 3 | March 2020}

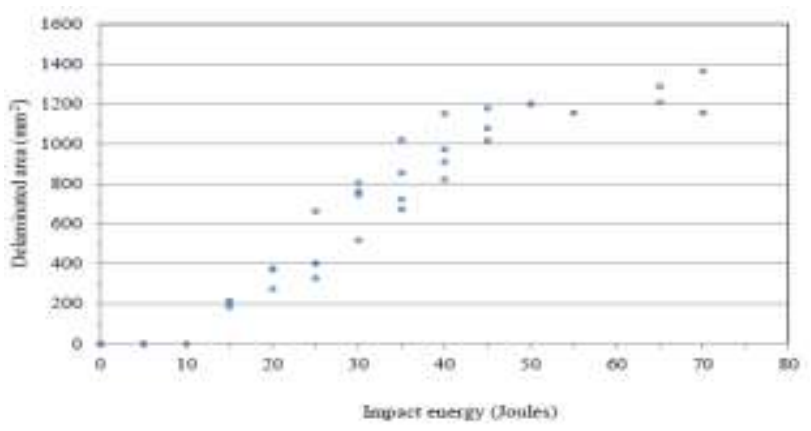

Figure 7 Damage initiation threshold

B. Application of Impact Load

The impact velocity corresponding to $15 \mathrm{~J}$ impact energy is calculated as follows:

$\mathrm{E}=\mathrm{mgh}$

Where $\mathrm{E}$ is the impact energy

Mass of the impactor, $\mathrm{m}=2.24 \mathrm{~kg}$

Acceleration due to gravity, $\mathrm{g}=9.81 \mathrm{~m} / \mathrm{s}^{2}$

Hence, $\mathrm{h}=\mathrm{E} / \mathrm{mg}=15 /(2.24 * 9.81)=0.683 \mathrm{~m}$

Impact velocity, $\mathrm{v}=\operatorname{sqrt}(2 \mathrm{gh})=3.659 \mathrm{~m} / \mathrm{s}$

Initial impact load was applied as $3.659 \mathrm{~m} / \mathrm{s}$, corresponding to $15 \mathrm{~J}$ of impact energy.

\section{VII.RESULTS AND DISCUSSION}

\section{A. Efficient Fiber Volume Fraction}

Further to the determination of critical velocity for different fiber volume fractions, it was found that matrix tension was the initial damage mode in the composite irrespective of fiber volume fraction. The variation of impact energy required to initiate damage due to matrix tension was analysed with respect to fiber volume fraction of the composite. The result is shown in Figure 8

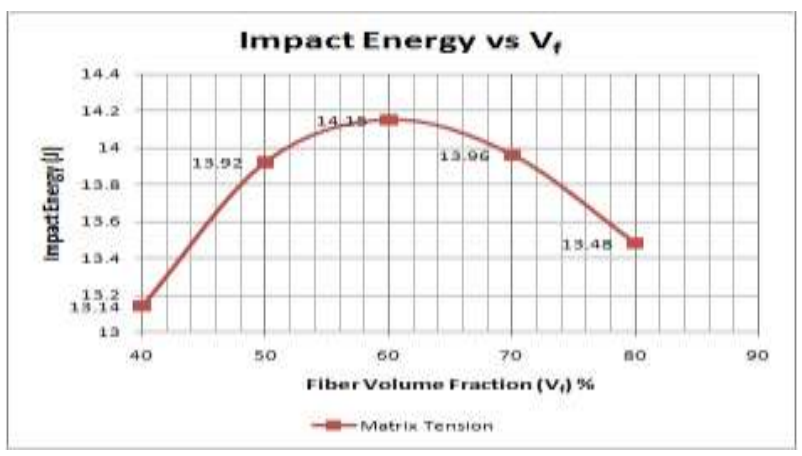

\section{Figure 8 Variation of impact energy with Vf}

It was found that the impact energy increases from a value of $13.14 \mathrm{~J}$ at $\mathrm{V}_{\mathrm{f}}=40 \%$ to a maximum value of $14.15 \mathrm{~J}$ at $\mathrm{V}_{\mathrm{f}}=60 \%$. The impact energy decreases with further increase in fiber volume fraction. Maximum energy is required to cause damage initiation at $\mathrm{V}_{\mathrm{f}}=$
- Peer Reviewed Journal

$60 \%$. The resistance to failure is maximum at $\mathrm{V}_{\mathrm{f}}=60 \%$ for T300/976 type of composite used in this analysis. Hence $\mathrm{V}_{\mathrm{f}}=60 \%$ is the most efficient fiber volume fraction

\section{B. Effect of Laminate Thickness on Impact Damage}

In order to determine the effect of laminate thickness on impact damage, for a composite layup of $[45 / 0 /-45 / 90]_{5 \mathrm{~s}}$ for fiber volume fraction of $60 \%$, analysis was conducted by keeping the mass of impactor as constant at $2.24 \mathrm{~kg}$, velocity of impactor $22.6 \mathrm{~m} / \mathrm{s}$ and by varying the laminate thickness as $0.1,0.2,0.3,0.4,0.5$ and $0.6 \mathrm{~mm}$ respectively (corresponding plate thicknesses 4, 8, 12, 16, 20 and 24mm). The variation of Hashin's Damage Criteria with plate thickness is shown in figure 9

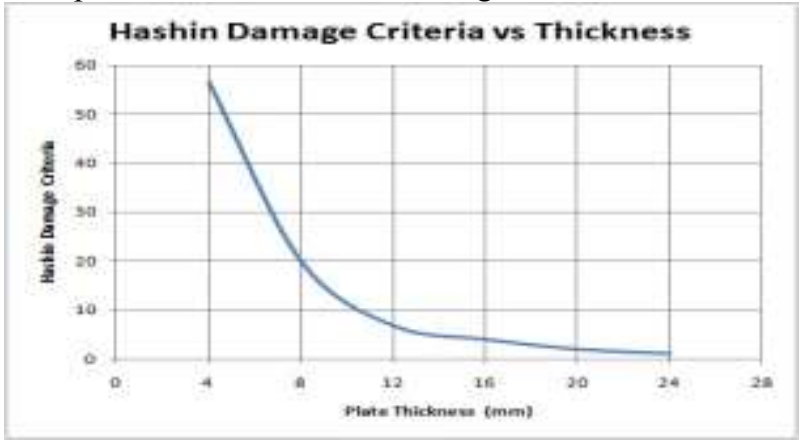

Figure 9 Variation of impact damage with plate thickness

It can be seen that the value of Hashin's Damage parameter decreases rapidly from a value of 55 at plate thickness of $4 \mathrm{~mm}$ to 7 at plate thickness of $12 \mathrm{~mm}$. This indicates a significant reduction in the amount of damage which occurs in the composite with increase in plate thickness. Beyond a thickness of $12 \mathrm{~mm}$, the reduction in the value of Hashin's Damage parameter is minimal. Hence it can be inferred that up to a thickness of $12 \mathrm{~mm}$, the increase in resistance to failure is considerable however beyond a thickness of $12 \mathrm{~mm}$, the increase in resistance to failure is marginal.

\section{Effect of Impactor Velocity}

In order to determine the effect of impactor velocity, for a composite layup of $[45 / 0 /-45 / 90]_{5 \mathrm{~s}}$, analysis was conducted by keeping the mass of impactor as constant at $2.24 \mathrm{~kg}$, fiber volume fraction $60 \%$, plate thickness $6 \mathrm{~mm}$ and by varying the impactor velocity as $1,3,5$ and $7 \mathrm{~m} / \mathrm{s}$ respectively. The variation of contact force developed at the contact interface with respect to impactor velocity is shown in Figure 10 
EPRA International Journal of Research and Development (IJRD)

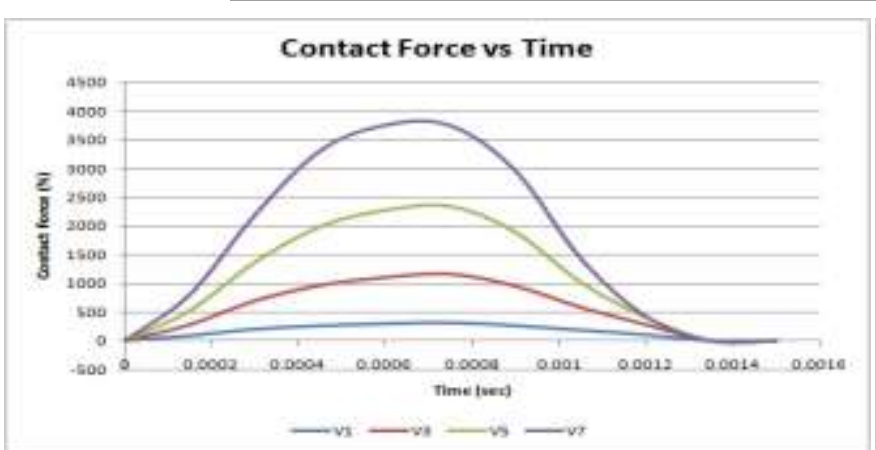

Figure 10 Variation of contact force for different impactor velocities

The contact force is found to increase with time for different impactor velocities. It reaches a maximum value $\mathrm{CF}_{\max }$ and thereafter decreases. The variation of the central deflection of the plate with respect to impactor velocity is shown in Figure 11

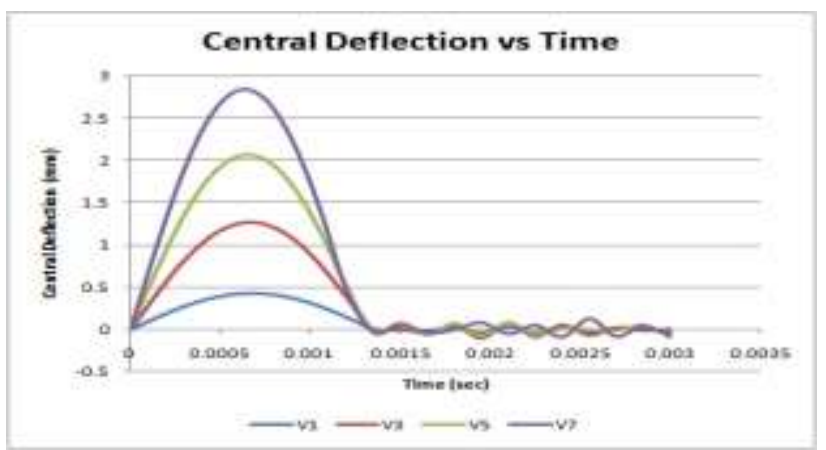

Figure 11Variation of central deflection of plate for different impactor velocities

The central deflection of the plate is found to increase with time for different impactor velocities. It reaches a maximum value $U_{\max }$ and thereafter decreases. It is observed that, as the velocity of impactor increases, the maximum contact force developed and maximum central deflection of the composite plate increases.

\section{Effect Mass of the Impactor}

In order to determine the effect of mass of the impactor, for a composite layup of $[45 / 0 /-45 / 90]_{5 S}$ for fiber volume fraction of $60 \%$, analysis was conducted by keeping the velocity of impactor as constant at $3.56 \mathrm{~m} / \mathrm{s}$, plate thickness as $6 \mathrm{~mm}$ and by varying the mass of the impactor. The variation of contact force developed at the contact interface with respect to impactor mass is shown in Figure 12

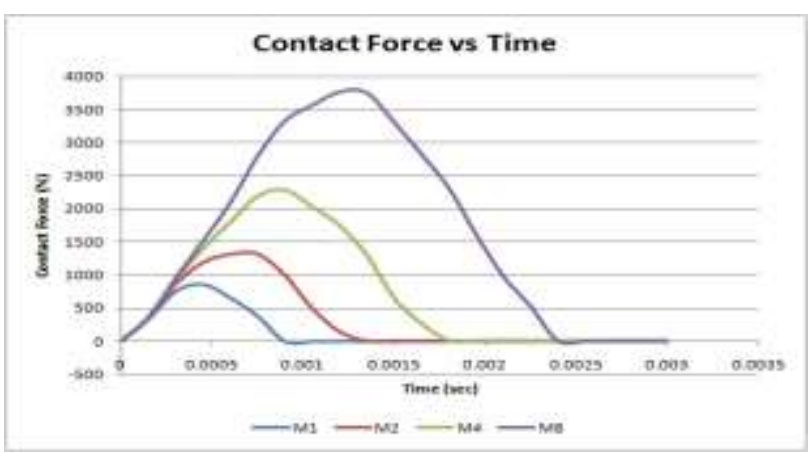

Figure 12 Variation of contact force for different impactor mass

The contact force is found to increase with time for different impactor mass. It reaches a maximum value $\mathrm{CF}_{\max }$ and thereafter decreases. The variation of the central deflection of the plate with respect to impactor mass is shown in Figure 13

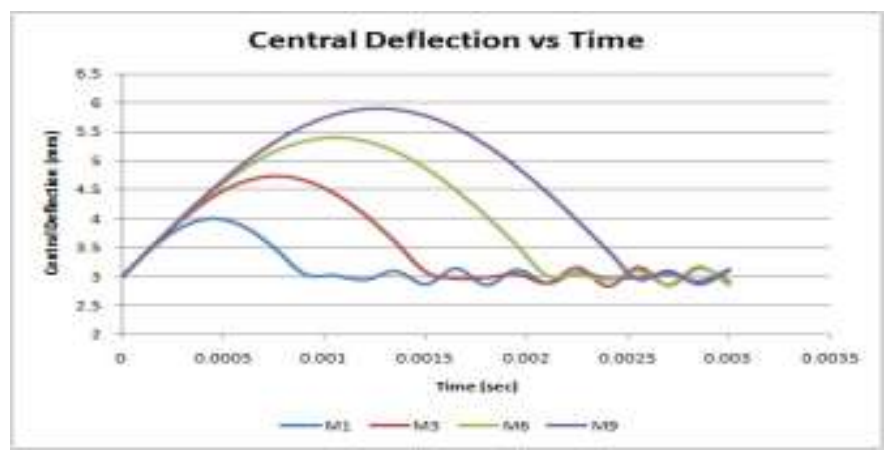

Figure 13 Variation of central deflection for different impactor mass

The central deflection of the plate is found to increase with time for different impactor mass. It reaches a maximum value $U_{\max }$ and thereafter decreases. It was found that, as the mass of the impactor increases, the contact force increases. But doubling the mass does not increase the maximum contact force by the same factor. The contact duration increases with an increase in mass of impactor which is indicated the shift in the peak values $\mathrm{CF}_{\max }$ and $\mathrm{U}_{\max }$ towards the right with time. It is also observed that, as the velocity of impactor increases, the maximum contact force developed and maximum central deflection of the composite plate increases.

\section{E. Effect of Boundary Conditions}

In order to determine the effect of boundary conditions of the composite plate, for a composite layup of $[45 / 0 /-45 / 90]_{5 s}$ for fiber volume fraction of $60 \%$, analysis was conducted by keeping the velocity of impactor as constant at $3.56 \mathrm{~m} / \mathrm{s}$, plate thickness as $6 \mathrm{~mm}$, mass of the impactor as $2.24 \mathrm{~kg}$ and by varying the boundary conditions 


\section{EPRA International Journal of Research and Development (IJRD)

of the plate as fully clamped and simply supported respectively. The variation of contact force developed at the contact interface with respect to boundary conditions is shown in Figure 14.

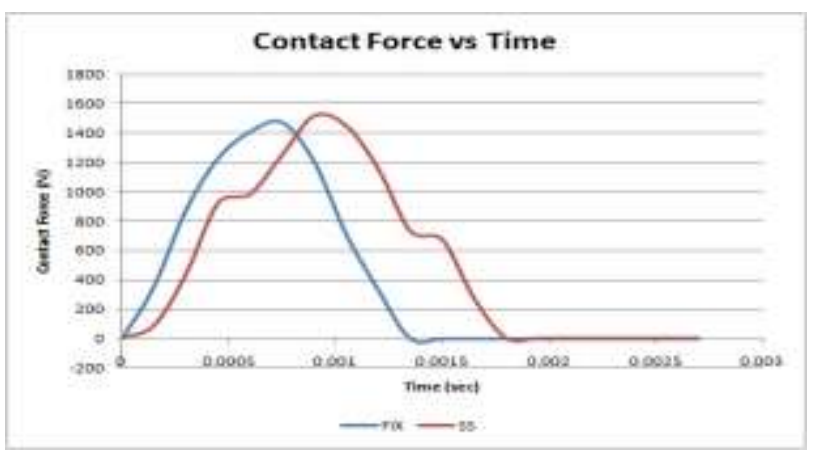

Figure 14 Variation of contact force for different boundary conditions

The contact force is found to increase with time for different boundary conditions of the composite plate. It reaches a maximum value $\mathrm{CF}_{\max }$ and thereafter decreases. It is observed that there is a steep increase in the contact force developed for a fully clamped (FC) configuration. However the increase in contact force for a simply supported (SS) configuration is much more gradual. This indicates that SS configuration is better suited to resist dynamic or shock impact loads since there is only a gradual buildup of contact forces in the contact interface. The variation of the central deflection of the plate with respect to boundary conditions of the composite plate is shown in Figure 15

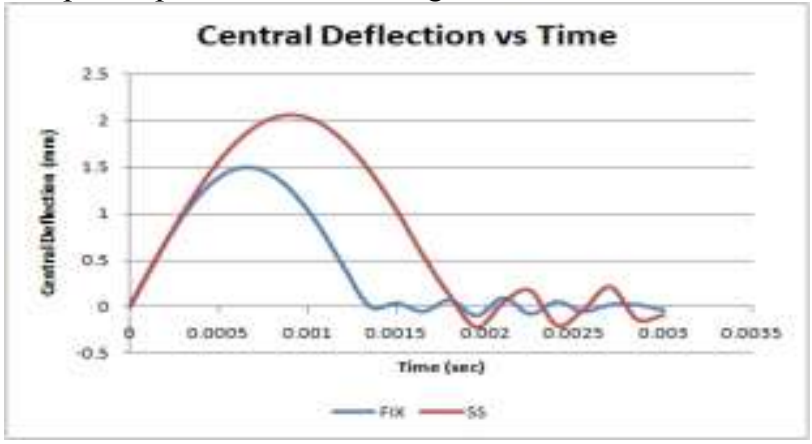

Figure 15 Variation of central deflection for different boundary conditions

The central deflection of the plate is found to increase with time for different boundary conditions of the composite plate. It reaches a maximum value Umax and thereafter decreases. Umax for a SS configuration is found to be higher than that of FC configuration. This indicates that the $\mathrm{FC}$ configuration is more rigid compared to a SS configuration.
The maximum contact force developed and central deflection of the plate is found to increase marginally for a simply supported configuration compared to a fully clamped configuration. The contact duration increases for a simply supported configuration compared to a fully clamped configuration, i.e. the structure experiences contact forces for a longer duration in SS configuration compared to fully clamped configuration.

\section{VIII.EMPRICAL MODELING}

In order to predict the maximum contact force CFmax and maximum central deflection of the composite plate Umax for any arbitrary value of impactor velocity and mass, empirical models were developed using the Method of Least Squares from the set of data values obtained in previous sections. The reliability of these models was checked using the coefficient of determination. In order to calculate coefficient of determination, correlation coefficient was initially calculated as

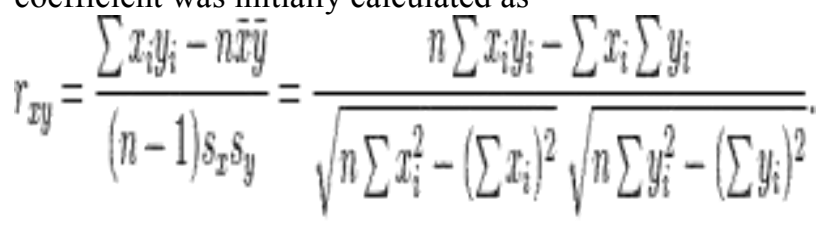

where $\mathrm{x}$ and $\mathrm{y}$ are results of measurements.

It is then squared to determine the coefficient of determination. It provides a measure of how well future outcomes are likely to be predicted by the model. If its value is close to 1 , the model is reliable. I

\section{A. Empirical Modeling of $\mathbf{C F}_{\max } \mathrm{vs} \mathbf{V}$}

The maximum values of contact force (CFmax) were taken from Figure 10 and its variation with impactor velocity is plotted in Figure 16.

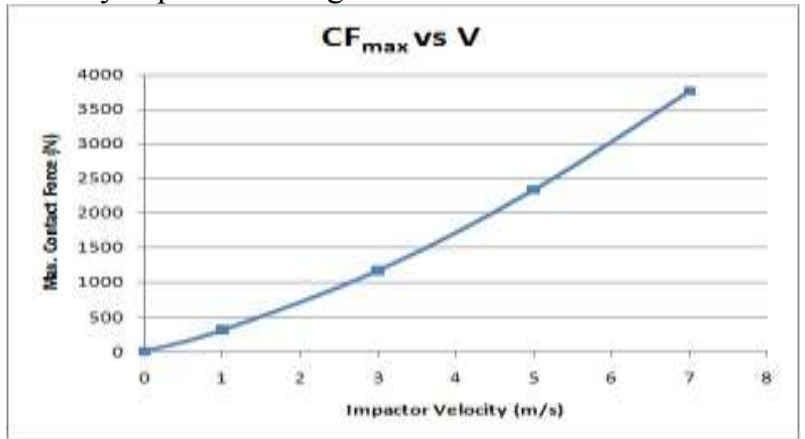

\section{Figure 16 Variation of maximum contact force with impactor velocity}

\section{B. Empirical Modeling of $U_{\max } \mathbf{v s} \mathbf{V}$}

The maximum values of central deflection (Umax) were taken from Figure 11 and its variation with impactor velocity is plotted in Figure 17. 


\section{EPRA International Journal of Research and Development (IJRD) \\ Volume: 5 | Issue: 3 | March 2020}

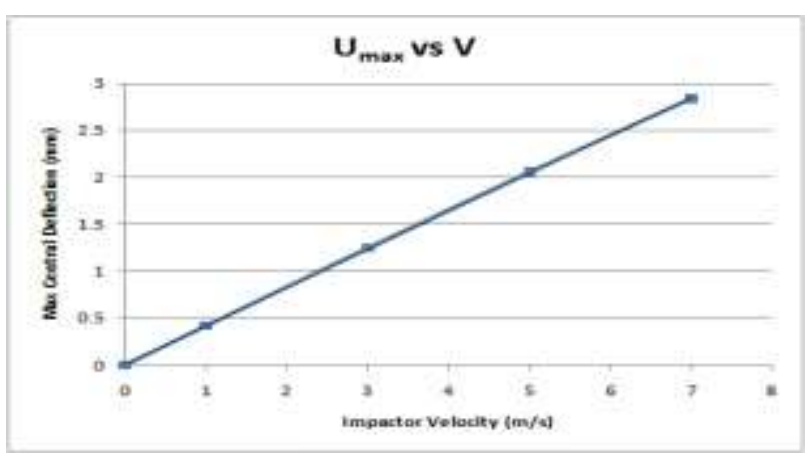

Figure 17 Variation of maximum central deflection with impactor velocity

C. Empirical Modeling of $\mathrm{CF}_{\max } \mathrm{vs} \mathbf{m}$

The maximum values of contact force $(\mathrm{CF})$ were taken from Figure 12 and its variation with impactor mass is plotted in Figure 18

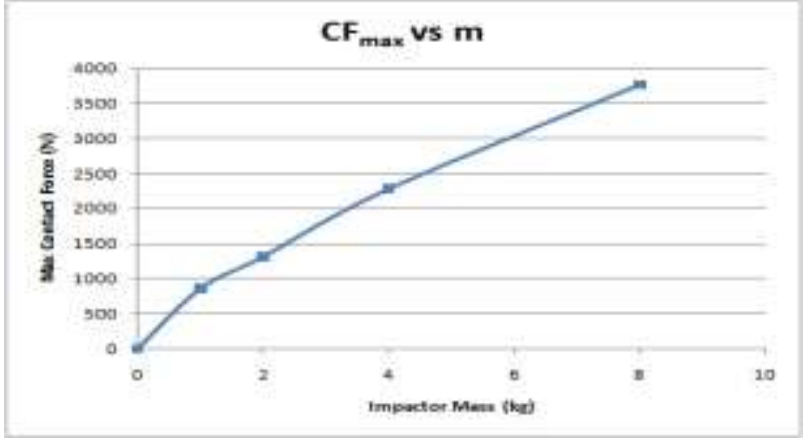

Figure 18 Variation of maximum contact force with impactor mass

D.Empirical Modeling of $U_{\max }$ vs m

The maximum values of central deflection (U) were taken from Figure 14 and its variation with impactor velocity is plotted in Figure 19

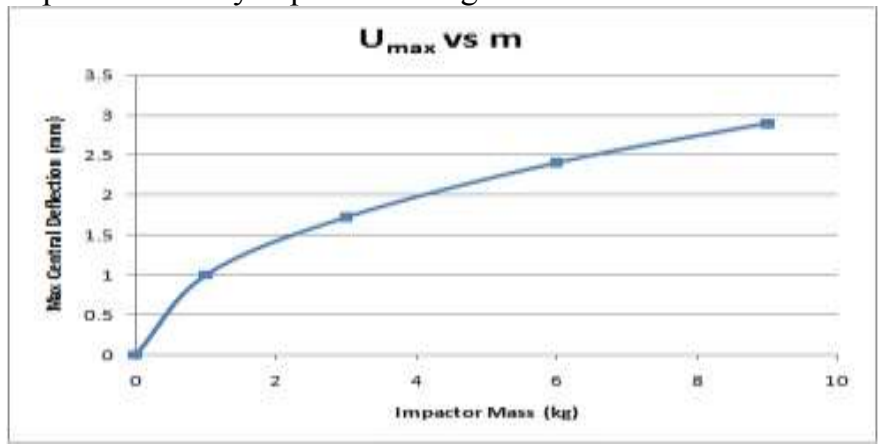

Figure 19 Variation of maximum central deflection with impactor mass

\section{IX.CONCLUSION}

The onset of matrix cracking and delamination which are the predominant damage modes in laminated composites subjected to impact loading depends on factors such as impactor mass, velocity and the properties of the composite. Hence in the present study the dynamic response of composite laminates under low velocity impact was investigated.

A laminated composite panel made of T300/976 graphite/epoxy fiber-reinforced laminates is subjected to transverse impact by a projectile with a spherical nose. Hashin failure model was adopted and analysis was done using $150 \times 100 \mathrm{~mm}$ composite specimen with a fiber volume fraction of $58 \%$. Its construction consists of 40 unidirectional T300 carbon fiber reinforced epoxy plies with a symmetric stacking sequence $[45 \mathrm{o} / 0 \mathrm{o} /-$ 45o/90o]5S, which achieve a total cured thickness near to 6 $\mathrm{mm}$ with a uniform cross-section over the entire surface. The laminated plate layup is defined such that the 0o fiber orientation is aligned with the lengthwise dimension. The impactor used was hemispherical in shape with a diameter of $16 \mathrm{~mm}$ and a mass of $2.24 \mathrm{~kg}$.

The initiation of damages in composite structures namely matrix tension, matrix compression, fiber tension, fiber compression were predicted. The effect of material properties, fiber volume fraction, laminate thickness, plate boundary conditions, velocity and mass of impactor on the impact damage were analysed. Variation of resistance to failure with laminate thickness and fiber volume fraction were identified. Empirical models were developed to predict the contact force and central deflection of the composite plate for a particular impactor mass and velocity. The appropriate boundary conditions were identified for different types of impact loading. Most efficient fiber volume fraction was identified for T300/960 type of graphite epoxy composite with a composite layup of $[45 / 0 /-$ $45 / 90] 5 \mathrm{~S}$. The following inferences can be derived from this study:

1. As the fiber volume fraction increases, the velocity required to initiate impact damage increases up to a fiber volume fraction of $60 \%$ and thereafter decreases. At Vf $=60 \%$, maximum energy is required to cause damage initiation. Hence $\mathrm{Vf}=$ $60 \%$ is the optimum fiber volume fraction for the given T300/epoxy composite.

2. Tensile failure is found to be the predominant failure mode for both fiber and matrix. Matrix failure was found to initiate first followed by fiber failure for all the fiber volume fractions.

3. As the thickness of the laminate increases, the amount of damage decreases. However, beyond a thickness of $12 \mathrm{~mm}$, the increase in resistance to failure is marginal.

4. As the velocity of impactor increases, the maximum contact force developed and maximum central deflection of the composite plate increases. 
5. The increase in maximum contact force CFmax with impactor velocity $\mathrm{v}$ is found to be quadratic

6. Maximum central deflection Umax is found to be proportional to impactor velocity.

7. As the mass of the impactor increases, the contact force and central deflection of plate increases.

8. The contact duration also increases with an increase in mass of impactor.

9. The increase in maximum contact force CFmax and maximum central deflection Umax with impactor mass $\mathrm{m}$ is found to be logarithmic.

10. Empirical models were developed for variation of maximum contact force CFmax and maximum central deflection Umax with respect to the velocity and mass of the impactor using the Method of Least Squares.

11. These empirical models were found to be reliable since the coefficient of determination is close to unity for all the models.

12. The maximum contact force and central deflection of the plate increases marginally for a SS configuration compared to a FC configuration.

13. The contact duration increases for a SS configuration compared to a FC configuration.

14. SS configuration is better suited for dynamic impact loading compared to a $\mathrm{FC}$ configuration because there is only a gradual increase in contact force for a SS configuration compared to a $\mathrm{FC}$ configuration a

15. When rigidity of structure is required, FC configuration is better as indicated by the lesser value of maximum central deflection of the plate.

\section{REFRENCES}

1. Alaattin Aktas, "Failure analysis of serial pinned joints in composite materials" -Indian Journal of Engineering \& Materials Sciences, Vol. 18, p.p 102 - 110, April 2011

2. Chian Fong Yen, Thomas Cassin and Joel Patterson; "Progressive failure analysis of thin walled composite tubes under low energy impact" ; U.S. Army Missile Command, Structures Directorate, technical papers 2007

3. Daihua Zheng, "Low velocity impact analysis of composite laminated plates” December 2007

4. De Moura, M.F.S.F. and Goncalves, J.P.M., "Modeling the interaction between matrix cracking and delamination in carbon-epoxy laminates under low velocity impact", Journal of Composites Science and Technology, pp. 1021-1027, 2004

5. Hsi-Yung, T., Wu and Fu Kuo Chang, "Transient dynamic analysis of Laminated Composite plates subjected to transverse impact" -Journal of
Computers and structures vol.31, No.3, pp. 453-466, 1989

6. Hyung Yun Choi and Fu-Kuo Chang, "A Model for Predicting Damage in Graphite/Epoxy Laminated Composites Resulting from Low-Velocity Point Impact" Journal of Composite Materials 26: 2134, 1992

7. Jones, R.M., Mechanics of Composite Materials, 2nd edition, Taylor \& Francis Co. 1999

8. Joseph Rakow, F., Alfred Pettinger, M., "Failure Analysis of Composite Structures in Aircraft Accidents"; Paper presentation, Annual Air Safety Seminar Cancun, Mexico, ISASI 2006, September 11-14 2006

9. M. A. Perez, L. Gil, S. Oller; "Non-destructive testing evaluation of low velocity impact damage in carbon fiber reinforced laminated composites" ULTRAGARSAS (ULTRASOUND), ISSN 1392-2114, Vol. 66, No. 2, 2011

10. Ramazan Karakuzu, Emre Erbil, Mehmet Aktas, "Damage prediction in Glass/Epoxy Laminates subjected to impact loading", Indian Journal of Engineering \& Materials Sciences, Vol. 17, pp. $186-$ 198, June 2010

11. 11. Reddy, J.N., The Finite Element Method. (Third Edition), TATA Mc Graw Hill, 1993

12. Sinha, P.K., "Composite materials and structures", Dept of Aerospace Engg, IIT Kharagpur, 2002 ; Available http://www.ae.iitkgp.ernet.in/ebooks/index.html.

13. Sun, C.T. \& Yang, S.H., "Contact law and impact responses of laminated composites", NASA technical papers- CR159884, Feb. 1980

14. Umar Farooq and Karl Gregory, "Theoretical and Computational Modeling of Pseudo-Damage Induced Approach for Failure Prediction of Low Velocity Impact on Fibrous Composite Panels", - European Journal of Scientific Research, ISSN 1450-216X, Vol.24, No.2, pp.197-210, 2008. 